\title{
MANAGED CARE, TECHNOLOGY ADOPTION, AND HEALTH CARE: THE ADOPTION OF NEONATAL INTENSIVE CARE
}

\author{
Laurence C. Baker \\ Ciaran S. Phibbs \\ Working Paper 7883 \\ http://www.nber.org/papers/w7883
NATIONAL BUREAU OF ECONOMIC RESEARCH
1050 Massachusetts Avenue
Cambridge, MA 02138
September 2000

We thank Michael Chernew and participants at the NBER meeting on industrial organization in health care for helpful comments. We thank Susan Schmitt for invaluable assistance with data analysis. This project was supported by funding from the National Institute for Child Health and Development R01-HD36914 and from the UCSF-Stanford Healthcare System. The views expressed herein are those of the authors and not necessarily those of the National Bureau of Economic Research.

(C) 2000 by Laurence C. Baker and Ciaran S. Phibbs. All rights reserved. Short sections of text, not to exceed two paragraphs, may be quoted without explicit permission provided that full credit, including (C) notice, is given to the source. 
Managed Care, Technology Adoption, and Health Care:

The Adoption of Neonatal Intensive Care

Laurence C. Baker and Ciaran S. Phibbs

NBER Working Paper No. 7883

September 2000

JEL No. I1

$\underline{\text { ABSTRACT }}$

Managed care activity may alter the incentives associated with the acquisition and use of new medical technologies, with potentially important implications for health care costs, patient care, and outcomes. This paper discusses mechanisms by which managed care could influence the adoption of new technologies and empirically examines the relationship between HMO market share and the diffusion of neonatal intensive care, a collection of technologies for the care of high risk newborns. We find that managed care slowed the adoption of NICUs, primarily by slowing the adoption of midlevel NICUs rather than the most advanced high-level units. Slowing the adoption of mid-level units would likely have generated savings. Moreover, opposite the frequent supposition that slowing technology growth is uniformly harmful to patients, in this case reduced adoption of mid-level units could have benefitted patients, since health outcomes for seriously ill newborns are better in higherlevel NICUs and reductions in the availability of mid-level units appear to increase the chance of receiving care in a high-level center.

Laurence C. Baker

Department of Health Research and Policy HRP Redwood Bldg. Rm T253

Stanford University

Stanford, CA 94305

and NBER

laurence.baker@stanford.edu
Ciaran S. Phibbs

Health Economics Resource Center

VA Medical Center

795 Willow Road

Menlo Park, CA 94025

and Stanford University

cphibbs@stanford.edu 


\section{Introduction}

Advances in medical technology have attracted widespread attention in recent decades, both for the substantial benefits apparently produced for patients and for the large costs entailed (Aaron, 1991, Newhouse, 1992, Fuchs, 1996). In the past, technological change in health care was fueled by a reimbursement system that graciously payed health care providers for using new innovations and generously compensated the developers and adopters of new technologies (Weisbrod, 1991). But now managed care appears to be eroding the pillars that supported this system. In particular, managed care has attempted to limit the use of some new technologies and reduced physician and hospital reimbursement, often focusing on reducing spending for new high cost technologies at the most advanced institutions. This could have powerful impacts on technological change, shifting demand for new innovations and potentially influencing the strategies of researchers and developers.

Given evidence that technological change could account for over half of recent health expenditure growth (Newhouse, 1992), managed-care-induced changes in the rate of technological change could have important impacts on health care costs. More importantly, they could have powerful impacts on patient care and on health outcomes. Evidence suggests, for example, that technological change has produced substantial changes in the prognosis for heart attack patients and high-risk newborns over the past 25 years (Cutler, McClellan, and Newhouse, 1998, Williams and Chen, 1982) Understanding the impact of managed care on technology change is thus important for assessing its impact on spending and patient welfare. From a public policy standpoint, understanding the implications of the growth of managed care is necessary for analysis of policies that might promote or inhibit further development of managed care.

In part because managed care came to prominence relatively recently, its impacts on technology change are as yet relatively poorly understood. While it appears common to believe that 
managed care is slowing the rate of technology diffusion, and that this will necessarily be harmful to patients, there is not strong evidence that could substantiate or refute this view. In fact, it is not immediately clear that managed care growth will slow diffusion for every technology or that slowed diffusion would necessarily be bad for patients. Growth in managed care could promote the use of some new technologies, particularly those that are seen as improving outcomes and reducing costs. Furthermore, reductions in the use of new technologies need not uniformly harm patients. There is evidence, for example, that excessive technology use occurred during the fee-for-service era, perhaps to the detriment of patients (e.g. Brook, 1989).

This paper investigates the relationship between managed care activity and the adoption of neonatal intensive care units (NICUs), hospital units that organize a range of equipment and personnel to care for newborns with low birthweight and other serious health problems. NICUs provide a good case for study for several reasons. A substantial portion of the diffusion of NICUs occurred during the 1980s and early 1990s, a time period in which managed care played an active role in the health care system in some areas. Since setting up and using a NICU is expensive, and since managed care plans often attempt to reduce their spending on expensive advanced services, growth in managed care could well influence NICU adoption. Finally, studying NICUs provides a strong chance to learn about the implications for patient care. Good data on the care of high-risk newborns is increasingly available, and research shows that NICUs can have important impacts on outcomes (Phibbs et al, 1996).

We begin in the next section by describing the impacts managed care could have on technology adoption. We then empirically examine the impact of HMO market share on the diffusion of NICUs using proportional hazard models. We find that hospitals in high HMO areas were less likely to adopt NICUs over 1984-1996 than hospitals in low HMO areas. We also find 
that HMOs did not affect the diffusion of the most sophisticated "high-level" NICUs in the most advanced hospitals, but rather that the reductions in adoption we observe were almost entirely confined to "mid-level" NICUs, which have less sophisticated capabilities.

Reductions in the diffusion of mid-level NICUs would have generated significant savings. From a welfare standpoint, though, savings must be considered alongside changes in the quality of patient care and health outcomes. In this case, the absence of mid-level NICUs may lead some newborns to receive care at high-level centers, where outcomes are frequently better (Phibbs et al, 1996). We use detailed data on all birth in California between 1990 and 1996 to study the impacts of NICU availability on care for high-risk newborns. We find that reductions in the availability of mid-level units are associated with improvements in outcomes for high risk newborns, counter to the typical assumption that managed-care-induced reductions in the availability of medical technology are uniformly bad for patients.

This work builds on other research that suggests the potential for managed care to influence the performance of health care markets broadly. A number of researchers have studied the effects of managed care on spending and insurance premiums (e.g. Baker, 1997, 1999, Baker and Corts, 1996, Feldman et al., 1993, Goldberg and Greenberg, 1979, Wickizer and Feldstein, 1995, Chernew, 1995, Feldman et al., 1986, McLaughlin, 1987, 1988, Noether, 1988, Robinson, 1991, 1996, Clement et al., 1992, Welch, 1994). None of these studies discussed the relationship between managed care activity and NICU adoption, although they provide reason to believe that managed care can influence market-level patterns of care and spending, which could contribute to changes in adoption.

While a number of papers examine the propensity of managed care organizations to use new technologies in the treatment of their patients (see Chernew et al, 1998), previous work on managed 
care and the adoption of new technologies by providers is limited. Cutler and Sheiner (1998) studied a wide range of hospital-based technologies and found evidence that hospitals in states with higher HMO market share had slower rates of adoption of some technologies during the 1980s and 1990s. Baker and Spetz (1999), though, used an index of hospital technological advancement and did not find significant evidence of an overall effect on managed care on hospital technology adoption. Some work examines MRI and finds that areas with high HMO market shares adopted MRI more slowly than low market share areas (Baker, 2000). A small number of studies have examined the impact of managed care on health care delivery and suggested that managed care can influence the health care patients receive, which may be a reflection of technology availability (e.g. Baker et al., 2000).

More generally, the literature on the adoption and diffusion of technologies is well developed, ${ }^{1}$ and provides a strong foundation for this study, particularly in that it consistently suggests that changes in the profitability of a new technology and other environmental factors (e.g. regulation) are important determinants of adoption patterns.

\section{Managed Care Activity and the Adoption of New Technologies}

Before the advent of managed care, health insurers typically paid health care providers using fee-for-service reimbursement, exercising very little oversight of the treatment decisions made by patients and their doctors. The desire of patients and physicians for ever more advanced (and

${ }^{1}$ See, e.g., Mansfield, 1968 and Reinganum, 1989. Examples of other health care technology studies are Anderson and Steinberg, 1984, Baker, 1979, Banta, 1980, Cutler and McClellan, 1996, Fendrick et al., 1994, Globerman, 1982, Hillman and Schwartz, 1985, Hillman et al., 1984, Lee and Waldman, 1985, Romeo et al., 1984, Salkever and Bice, 1976, and Russell, 1977. Examples of work in other areas using techniques similar to those use here are Rose and Joskow, 1990, Saloner and Shepard, 1995, Levin, Levin, and Meisel, 1987, and Hannan and McDowell, 1984. 
costly) health care, coupled with the readiness of third party payers to meet the costs of providing it, generated ample encouragement to developers, adopters, and users of new technologies for speedy advancement (Weisbrod, 1991).

"Managed care" describes a collection of health plan activities designed to reduce the high levels of utilization and spending that accompanied unfettered fee-for-service medicine. The activities that fall under the rubric of managed care can be loosely placed in three groups. First, managed care plans attempt to alter financial incentives. Rather than paying on a fee-for-service basis, many managed care plans pay physicians using capitation or other reimbursement schemes that do not directly reward physicians for performing more, and more expensive, treatments. Second, managed care plans often assert control over many of the treatment decisions made for patients. Many managed care plans, for example, require authorization before conducting expensive tests and procedures, monitor the use of resources by providers, or use gatekeeper physicians who must approve all referrals to specialists. Finally, managed care plans often search for a set of physicians and hospitals with which they desire to contract, negotiate contracts with just these providers, and then restrict their members to use the chosen providers. Typically, plans are thought to search for low-cost providers and attempt to exploit their control over the utilization of increasing numbers of patients against a surplus of health care providers to extract concessions. Since the belief on the part of plans is typically that fee-for-service medicine was characterized by excessive use of expensive tests and procedures, the have frequently focused their use of these tools on curbing the use of these services and reducing the amount they pay for them (Miller and Luft, 1997).

Growth in managed care could influence the incentives associated with adopting a new technology in several ways. First, managed care could change the expected profitability of a new technology. Models of technology adoption frequently suggest that changes in profitability will 
change adoption timing. ${ }^{2}$ Typically, models suggest that firms with higher expectations about profitability will tend to adopt earlier than firms with lower profitability projections. If managed care reduces the expected profitability of a new technology, firms in high managed care areas will tend to adopt later than otherwise identical firms in areas with less managed care, and vice versa.

The effects of managed care on the profitability of a service or technology can be illustrated in a simple framework. Consider a provider that serves $N$ patients, $\phi_{t}$ of whom are enrolled in HMOs in period $t$, and the remaining $1-\phi_{t}$ of whom are covered by fee-for-service (FFS) insurers. The provider can price discriminate between HMO and FFS patients. In period $t$, a provider who has the technology earns profits:

$$
\pi_{t}=N \phi_{t} p_{H} \alpha_{H}+N\left(1-\phi_{t}\right) p_{F} \alpha_{F}-c\left(q_{t}\right)
$$

where $p_{H}$ and $p_{F}$ are the prices that can be charged to HMO and FFS patients for the service supported by the technology (e.g. a NICU day), $\alpha_{H}$ and $\alpha_{F}$ are the fractions of HMO and FFS patients who demand the service, $c$ denotes the cost function, and $q_{t}=N\left[\phi_{t} \alpha_{H}+\left(1-\phi_{t}\right) \alpha_{F}\right]$ is the total units of service produced in period $t$.

Increases in HMO market share would impact profits through both prices and quantities. HMOs are assumed to have highly elastic demand, and bargain aggressively to obtain low prices, while FFS patients often have little incentive to incorporate price into their decisionmaking. Price discriminating providers may thus be expected to set $\mathrm{p}_{\mathrm{F}}>\mathrm{p}_{\mathrm{H}} \geq \mathrm{c}^{\prime}$, and shifting patients from FFS insurance to HMOs will reduce revenues. Second, $\alpha_{\mathrm{F}}$ need not equal $\alpha_{\mathrm{H}}$ if managed care plans and FFS plans differ in the care they provide to their patients. In the case of many expensive new

\footnotetext{
${ }^{2}$ See, e.g., Reinganum, 1989, or Rose and Joskow, 1990 for discussions.
} 
services, HMOs are thought to be less likely to refer patients for services $\left(\alpha_{F}>\alpha_{H}\right){ }^{3}$

A full assessment of the profitability of adoption would incorporate effects on other services. A new technology may be a substitute or complement for services already offered. Adopting new technologies has also been viewed as a way of attracting business. Under fee-for-service, doctors and patients frequently selected hospitals with the most advanced technologies, even if they only needed relatively simple services. In this era, anecdotal evidence suggests that some hospitals adopted NICUs to attract deliveries, and thus introduce the hospital to a new family who might use it for other services in the future. Selectively contracting managed care plans seem to make decisions about the providers their members will use in very different ways. Although they might value the presence of technologies in deciding who to contract with, managed care plans also place weight on costs, so that adopting a new technology that would raise the contract price a hospital could offer would tend to be discouraged.

Some literature on technology adoption also stresses the importance of strategic interactions between firms (e.g. see Vogt, 1997). The specific assumptions and focus of strategic interaction models, and hence their predictions for diffusion processes, vary from model to model, but the importance of these factors is increasingly clear. Most models focus on the returns to being the first adopter in a market and the incentive for a firm to delay after a rival has adopted. It is not difficult to believe that managed care could influence strategic interactions, although it is difficult to predict

${ }^{3}$ There are other potential mechanisms by which managed care growth could impact the profitability of having a technology. One possibility is that $\partial \alpha_{\mathrm{F}} / \partial \phi$ is not zero. HMOs use various mechanisms to encourage physicians working for them to practice in accordance with the organizations' preferences. These physicians may incorporate changed practice patterns when they care for non-HMO patients. Alternately, demand may be shifted through effects of HMOs on FFS insurers. As managed care activity increases, the competitive pressure felt by traditional insurers may also increase, leading to changes in their behavior (e.g., Baker and Corts, 1996, Feldman and Dowd, 1986, Frank and Welch, 1985, Goldberg and Greenberg, 1979). 
the direction of the effect. If the providers that initially win managed care contracts have an advantage in negotiations in subsequent years, and HMOs value the presence of a NICU in the choice of providers to contract with, growth in managed care could increase the premium associated with first adoption. Rivals of the first adopter might then perceive that they should immediately adopt, leading to rapid adoption throughout the market. On the other hand, rivals could perceive that the opinions of managed care plans with respect to the quality of hospitals will have been formed based on the initial adoption so that there is little to be gained by subsequent adoption, and choose to postpone adoption which would raise the mean time to adoption as HMO market share rises. In formal modeling, the direction of the strategic effects would depend on the specific assumptions about the preferences of managed care organizations, and the expectations of hospitals about the returns to various adoption scenarios.

Although these theories make clear the potential for managed care growth to impact technology diffusion in health are, in the case of NICUs (and most technologies), it is not clear a priori which way each of these effects would go or which would be most important, leaving the net impact of managed care on adoption patterns ambiguous.

\section{Neonatal Intensive Care}

Neonatal intensive care units are typically units of hospitals set up with their own beds and equipment and staffed by pediatricians with advanced training in neonatology, specialized nurses, and other specialized staff. Any given NICU contains a range of equipment and service capabilities that collectively represent the NICU "technology" that we study. Hospitals that wish to offer NICU 
services do so by setting up and staffing a NICU in their hospital. ${ }^{4}$

Setting up and running a NICU is quite costly. Observation of some hospitals in the San Francisco area suggests that setting up the equipment and physical plant can cost between $\$ 125,000$ and \$200,000 per bed, depending on the specific services offered and local circumstances. Beyond the cost of installation, specialized staff salaries and other operating costs can be very high. The patient charges associated with a NICU stay vary depending on the complexity of the infant's condition, but it is not difficult to run up bills of $\$ 50,000$ or more for a moderate length NICU stay. CIGNA HealthCare reported in 1992 that the average charge for extremely preterm infants was more than $\$ 89,000$ (CIGNA, 1992). While they are expensive, NICUs can have powerful impacts on the prognosis for high-risk newborns, substantially lowering mortality rates for severely ill newborns and improving non-mortality outcomes for other sick infants (Williams and Chen, 1982).

All insurers we are aware of, including managed care plans, cover medically indicated NICU care. Managed care plans appear, however, to have been quite vigilant about the use of NICUs. In many HMOs, NICU patients are the biggest single group of high cost patients (Society of Actuaries, 1996), and a large amount of work suggests that managed care plans devote particular attention to the use of high cost services (Miller and Luft, 1997).

Some of our analysis of diffusion and health impacts distinguishes different types of NICUs. Today, it is common to classify hospitals offering care for newborns into one of three groups. Essentially all hospitals that host planned deliveries are equipped with a "well baby nursery" containing basic equipment for the care of healthy newborns and those with very minor medical

\footnotetext{
${ }^{4}$ The specific arrangements can vary from hospital to hospital. Some hospitals develop their NICUs as separately set up and staffed units in the hospital. Other hospitals set up NICU-like services, but do not designate them a separate unit in the hospital. Some hospitals contract with physician groups or other entities that technically own the unit set up within the hospital. The practical differences between these arrangements are typically small.
} 
problems. Hospitals that offer only this level of service have no NICU and are classed as level I hospitals. At the other end of the spectrum are level III units (which we also refer to as "high level" units, and some refer to as "regional" or "tertiary" NICUs), which provide a full range of specialized neonatal care for the most seriously ill newborns, including long-term mechanical ventilation, subspecialty consultants, and surgeries for newborns. Between level I and level III units, level II units (which we also refer to as "mid level" units and some refer to as "community" NICUs) provide some of the advanced services of level III units, but not all. Many of these units do not provide mechanical ventilation for extended periods of time. These units also typically do not have the staff and related equipment for treating rare and very serious cases, or the staff and equipment to support complex neonatal surgeries.

The diffusion of NICUs spans a period of more than 30 years. The first units identifiable as NICUs were set up in mid 1960s, and there was some diffusion during the 1970s. The early diffusion was relatively slow and confined mainly to large and advanced hospitals that set up what were then, and have been continually upgraded to remain, high-level units. More widespread diffusion of NICUs during this time was inhibited by the facts that the techniques and equipment for caring for high-risk newborns were not accessible to most hospitals and the number of trained neonatal specialists was limited. During the 1980s and 1990s, though, the techniques for caring for high-risk newborns became better developed and the number of trained specialists grew. Thus, this period saw more rapid diffusion of NICUs outside of the most advanced hospitals, the bulk of which was mid-level units. Other factors also drove the spread of NICUs during this period. One was the expanding effort to improve health outcomes among newborns, which expanded the set of conditions that seemingly "required" either treatment in a NICU or the presence of a NICU as a backup capability in the hospital of birth. Many obstetricians and pediatricians thus began to argue 
that keeping an active obstetrics unit operating, particularly in an urban area, would require a hospital to have a level II NICU or better. Hospitals may also have viewed adoption of a mid-level NICU as a way of attracting deliveries to the hospital. Since births are a common first point of introduction to the health care system for young families, and hospitals chosen for births are often chosen for other care later, attracting births was perceived by many hospitals as an effective strategy to build demand. Against the backdrop of this diffusion, however, the incentives associated with managed care growth were changing the financial and strategic picture associated with adoption.

\section{HMO market share and the diffusion of NICUs}

\section{$\underline{4.1 \text { NICU Data }}$}

We analyze hospital adoption of NICUs using data from the American Hospital Association (AHA) survey of hospitals, which inquires about a range of hospital characteristics, including the presence of various kinds of hospital units. Data on the NICUs is available from the AHA survey for 1980 and 1982-1996.

To form our main sample, we selected non-federal general medical and surgical hospitals and children's hospitals in the continental United States that were surveyed in $1980 .^{5}$ Each hospital was assigned a market area, defined as the Health Care Service Area (HCSA) ${ }^{6}$ in which it was located. Hospitals in very rural areas may behave quite differently than hospitals in other areas, so

\footnotetext{
${ }^{5}$ The restriction that the hospitals had to be surveyed in 1980 eliminates some hospitals that are only observed beginning in subsequent years. The majority of these hospitals are the entities that resulted from hospital mergers.

${ }^{6} \mathrm{HCSAs}$ are groups of counties constructed to approximate markets for health care services based on Medicare patient flow data (Makuc et al., 1991). In all, there are 802 HCSAs covering the entire continental United States. As an alternative to Metropolitan Statistical Areas, HCSAs provide smaller units of analysis specifically defined to represent health care markets, as well as a more representative set of markets for study.
} 
we excluded hospitals in areas with populations under 25,000. This left 5,426 hospitals. Because we wanted to restrict the analysis to hospitals that were candidates for adoption of a NICU, we included hospitals that had an active obstetrics unit in 1980, had at least 50 births in 1980, or were a children's hospital. This removed 1,102 hospitals. Finally, we excluded 133 hospitals with missing 1980 NICU data. This left us with an analysis sample of 4,191 hospitals.

We followed each hospital as far as possible by linking AHA surveys. We identified hospitals that adopted NICUs, and the year of adoption based on answers to survey questions about the number of beds the hospital had in a "neonatal intensive care unit" or in a "neonatal intermediate care unit." We classified hospitals as having a NICU in a given year if they had beds in neonatal intensive or intermediate care units. We identified the year of adoption as the first year of the first consecutive pair of years in which the hospital said they had a unit. Hospitals that could not be followed all the way to 1996 were treated as censored. ${ }^{7}$

In some analyses, we separate high-level and mid-level units. We classified hospitals as having a high-level NICU in a given year if they had at least some "neonatal intensive care" beds and the sum of the beds reported in their "neonatal intensive care" and "neonatal intermediate care" units was more than 15 . We classified hospitals as having a mid-level NICU if they said they had at least some "neonatal intensive care" beds, but the sum of their "neonatal intensive care" and "neonatal intermediate care" beds was 15 or less, or if they said that they only had "neonatal intermediate care" beds, regardless of the number. We believe that this classification will approximate mid-level and high-level units as described above. Most high-level units are large and

\footnotetext{
${ }^{7}$ The primary reasons for censoring was hospital closure or merger. Hospitals that merged were treated as censored because the behavior of a merged entity might be quite different than the behavior of each constituent hospital, so assigning adoption information from a merged entity to each of the constituent hospitals seemed inappropriate.
} 
are called "neonatal intensive care units" by their hospitals. Mid-level units are typically smaller and are sometimes not termed "neonatal intensive care units". 8

We do not attempt to account for hospitals that shut down their unit or change its type. In practice, these kinds of changes appear to be rare. For example, in California, where we have detailed data on NICU availability by hospital for 1986-1997, we observe no cases of hospitals changing from a level II unit to a level III unit or vice versa. Two hospitals were observed to close a unit during this time.

\subsection{HMO Market Share Data}

We measure the level of managed care activity in each HCSA using data on HMO market share (i.e. the percent of the population enrolled in HMOs). "Managed care" is not well defined and there are many types of managed care organizations, all of which could conceivably exert influence on technology diffusion processes. We use HMO market share since good geographically detailed data on HMOs is available for the time period under study and suitable data on other types of managed care plans like PPOs and POS plans are not. We expect that focusing on HMO activity will not strongly bias the results since HMOs were by far the most prevalent form of managed care during much of the time that neonatal intensive care was diffusing, and thus HMO activity probably provides a good proxy for the general level of managed care activity at this time. Even in more recent years, the presence of HMOs is likely a good proxy for the overall presence of strong

\footnotetext{
${ }^{8}$ To investigate the validity of our AHA measures, we compared our data with data for California hospitals derived from state filings and contact with hospitals that divides hospitals into 4 groups: level I, II, and III units as described above, and level II+ units intermediate between level II and III units. We split level II+ hospitals based on volume into small (mean census $<15$ ) and large (mean census $>15$ ) units. Of the California hospitals that we classified as high-level based on the AHA data in 1995, 19 of 21 were large level II+ or level III in the California data. Of the hospitals we classified as mid-level, 68 of 89 were level II or small II+ in the California data.
} 
managed care organizations since HMOs tend to use more stringent utilization management and have been more aggressive in reducing payments to providers than other forms of managed care plans like PPOs.

Conceptually, at any given time, the decision about whether and when to adopt a NICU should be a function of the current level of HMO market share and the expectations about future levels. Diffusion patterns for NICUs over 1980-1996 should thus cumulatively be functions of the actual levels of market share in each year and the expectations about future levels held at each point during 1980-1996. Measures of the expectations of hospital managers are not available. We classify HCSAs based on the average market share over the years 1990-1996. We expect this to be a reasonable proxy for actual and expected HMO market shares during 1980-1996 for two reasons. First, areas that had high average 1990-96 HMO market shares also tended to have high market shares in other years. Using MSA-level data available in 1983 and again in 1990-1996, we find that the correlation between 1990-1996 average market share and 1996 market share is 0.94. Correlations with 1990 and 1983 market share are 0.96 and 0.62, respectively. Second, areas that had high average 1990-96 HMO market shares also tended to have high growth in market share over 1983-1996. The MSA-level correlation between 1990-1996 average market share and changes between 1983 and 1996 is 0.73 . If hospitals were able to forecast HMO growth in their areas with some degree of accuracy, hospitals in areas with high 1990-1996 average market share would also have had higher expected future market share levels at any given time during this time period.

The estimates of market share we use were constructed using data from the Group Health Association of America (now the Association of American Health Plans) and/or Interstudy reports of total enrollment and counties served for all HMOs operating in the United States in each year 1990-1996. Using this data, county-level estimates were constructed by apportioning the enrollment 
of each HMO among the counties served based on county population and distance from HMO headquarters, and estimates for HCSAs and MSAs were constructed by aggregating the county-level estimates (Baker, 1997). The nationwide mean of the 1990-96 average market share, weighted by population, is $17.8 \%$. Across HCSAs in the sample, 1990-96 average market shares range from 0 to $48.3 \%$.

\section{$\underline{4.3 \text { Trends }}$}

Table 1 summarizes NICU adoptions observed in our sample. By the time of the survey in 1980, 413 of the 4,191 hospitals had NICUs operating. Over the next 16 years, an additional 767 hospitals adopted NICUs. Estimates of the cumulative adoption probability derived from KaplanMeier estimates of the survival curve (with "survival" indicating non-adoption) rise from about $10 \%$ in 1980 to nearly $30 \%$ in 1996.711 hospitals are censored before 1996, when all remaining hospitals are censored. The majority of these are censored because they close or merge during the time period, and the large number of hospitals in this category is consistent with overall trends in the hospital industry.

The majority of the adoptions we observe are mid-level units. Figure 1 plots the number of hospitals with different types of NICUs. Up through 1980, 224 hospitals had adopted high level units, and 189 had adopted mid-level units. Thereafter, 686 hospitals adopted mid-level units, and only 81 adopted high-level units. Most of the post-1980 adoptions of high-level units took place in the early 1980s. 37 of the $81(45 \%)$ occurred in or before 1985. This is consistent with anecdotal evidence that the majority of academic medical centers and other advanced hospitals that were candidates for high-level adoption adopted their units early on, and subsequent adoption was concentrated in mid-level units in other hospitals. 


\subsection{Hazard models of the relationship between HMOs and NICU diffusion.}

We now turn to an examination of the effect of HMOs on NICU adoption. Hazard models provide a natural framework for modeling adoption probabilities (e.g. Rose and Joskow, 1990, Cutler and McClellan, 1996, Baker, 2000). Denoting the cumulative probability that hospital $i$ has a NICU at time $t$ by $F_{i}(t)$ and the corresponding density function as $f_{i}(t)$, the hazard is defined as the instantaneous probability that hospital $i$ acquires a NICU at time $t$ conditional on not having acquired either up to that point: $\lambda_{i}(t)=f_{i}(t) /\left[1-F_{i}(t)\right]$. Following previous literature, we parameterize the hazard using a proportional hazard form: $\lambda_{i}(t)=\lambda_{0}(t) \cdot \exp \left(x_{i}(t)^{\prime} \beta\right)$ where $x_{i}(t)$ denotes the (potentially time varying) covariates that determine the proportionality in the hazard and $\lambda_{0}(t)$ is the baseline hazard.

The standard proportional hazard framework must be adapted slightly for our data, which consist of annual surveys skipping 1981, so the intervals during which adoptions occur are observed but not the exact timing of the adoption. In addition, some hospitals adopted prior to 1980 so their adoption times are left censored. To adapt the framework, let $y$ denote the times at which surveys were conducted: $y_{1}=1980, y_{2}=1982, y_{3}=1983, \ldots, y_{15}=1995, y_{16}=1996$. For convenience define $y_{0}$ $=0$. Then, let $t=1, \ldots, 16$ index time periods so period $t$ covers $\left(y_{t-1}, y_{t}\right]$. Then we can

define $\gamma(t)=\ln \left(\int_{y_{t-1}}^{y_{t}} \lambda_{0}(\tau) d \tau\right)$ to be the logarithm of the integrated baseline hazard of adoption

over period $t$. The cumulative probability of adopting a NICU by the end of period $t$ is given by:

$$
F_{i}(t)=1-\exp \left[-\sum_{s=1}^{t} \exp \left(x_{i}(s)^{\prime} \beta+\gamma(s)\right)\right] .
$$

Denote by $t_{i}{ }^{*}$ the first period in which a hospital is observed to have a NICU or is censored. The probability of adopting during the period is $F_{i}\left(t_{i}{ }^{*}\right)-F_{i}\left(t_{i}{ }^{*}-1\right)$. The probability that a hospital has not 
adopted by that time is $1-F_{i}\left(t_{i}{ }^{*}\right)$. Letting $\delta_{\mathrm{i}}=1$ for hospitals that adopt and $\delta_{\mathrm{i}}=0$ for hospitals that are censored, the likelihood function for the data is given by:

$$
L(\gamma, \beta)=\prod_{i=1}^{N}\left[F_{i}\left(t_{i}^{*}\right)-F_{i}\left(t_{i}^{*}-1\right)\right]^{\delta_{i}}\left[1-F_{i}\left(t_{i}^{*}\right)\right]^{\left(1-\delta_{i}\right)}
$$

We estimate (3) by maximum likelihood, using a non-parametric baseline (Prentice and Gloeckler, 1978, Meyer, 1990). In addition to measures of HMO market share, we include a set of hospital and other area characteristics as covariates in the models. Included hospital characteristics are the average bed size of the hospital and dummy variables for hospitals affiliated with medical schools, other teaching hospitals, and childrens hospitals. A set of area controls is designed to account for the degree of urbanization and includes the market population, the area population per square mile, and the percent of the population that lives in an urban area. The models also control for a standard set of market demographics reflecting the age, sex, race, education, and income of the population. Finally we include controls for the number of births per 1000 population in the area, and the percent of newborns below 2500 grams. We measure all of the area variables as of 1996 since these levels seem likely to capture both actual levels of these variables over preceding years and the expectations of hospital managers about trends in their marketplace over 1985-1996. Table 2 summarizes the covariates in the regressions.

We expect the effect of managed care to be stronger after the mid 1980s, when managed care began to play a stronger role in the health care system. Our examination of the proportionality assumption also suggested that the effects of many of the covariates changed over time. We thus interact all variables with an indicator for years before 1985 and years after, estimating separate coefficients for the earlier and later period. (About half of the adoptions in the sample occur before 1985 and about half after.) We experimented with other years as the breaking point, and with 3 
periods instead of 2 , and found consistent results.

Table 3 presents estimation results for coefficients of interest. The first column presents results from a model in which average 1990-1996 market share is entered linearly. The effect in 1985 and after is negative and statistically significant, suggesting that increases in market share are associated with reductions in the adoption hazard. The relative hazard for HMO market share is given by $\exp (\beta)$ and is shown in brackets. The results indicate that each 10 percentage point increase in the average 1990-1996 market share is associated with about a 15\% reduction in the adoption hazard. ${ }^{9}$ Before 1985, areas with higher market shares did not have significantly different adoption patterns.

The second column shows results from a model in which the linear HMO market share is replaced by a dummy for areas with market shares over $15 \%$. This grouping will dampen the effects of any measurement error in the market share estimates. Like those in column 1, these results suggest substantial effects of HMO market share on adoption units in the later time period. In 1985 and later, hospitals in areas with market shares over $15 \%$ had adoption hazards about $40 \%$ lower than hospitals in low market share areas.

There may be characteristics of areas that are not accounted for in the models shown in columns 1 and 2. For example, some states have certificate of need programs or other laws that govern the adoption of new medical technologies. The models shown in columns 3 and 4 include state dummies to control for area characteristics. The results are substantively the same as those shown in columns 1 and 2: negative and significant effects of HMO market share in the post 1985

\footnotetext{
${ }^{9}$ It is important to note that, although results are reported using the metric of 1990-1996 average
} market share, the results reflect the effects of HMOs built up over a range of prior years in which the actual market share levels were generally lower, and potentially also reflect the expectations about future levels of HMO market share, which may be higher than the 1990-1996 average. 
period, and no significant effect in the pre-1985 period..$^{10}$

To get a sense for the magnitude of the effect, Figure 2 plots the cumulative adoption probabilities for a hospitals with average characteristics in a market with market share $10 \%$ and a market with 30\%, predicted based on the model with state dummies (Table 3, column 3). By 1996, the predicted cumulative adoption probability was $16.9 \%$ in low market share areas, as opposed to $13.2 \%$ in high market share areas, a difference of 3.7 points. Reducing the overall probability of adoption by 3.7 percentage points for our sample hospitals would have resulted in 155 fewer NICUs adopted by 1996 , a reduction of $13 \%$.

An assumption of proportional hazard models with censored observations is that censoring is independent of adoption, that is, that $F(t)$ is identical for both censored and non-censored observations. Some of the hospitals in our sample are censored because they close or merge, and it may be that these have different adoption hazards than hospitals that do not. To investigate the impact of pooling hospitals and assuming fixed $F(t)$, we reestimated our adoption hazard model separately for hospitals that close or merge between 1980 and 1996 and hospitals that do not. For hospitals that do not close or merge, the market share coefficient for 1985 and later is -0.155 $(\mathrm{se}=0.061)$. For hospitals the do, the coefficient is $-0.300(\mathrm{se}=0.273)$. These results suggest that managed care slowed adoption for both groups, although the effect on hospitals that closed or merged is of borderline statistical significance, probably because of the limited sample size. They

\footnotetext{
${ }^{10}$ These results are robust to a variety of respecifications, including: (1) allowing all of the (nonHMO) covariates are allowed to be time-varying; (2) including additional controls for the fraction of inpatient days covered by Medicaid, whether the hospital is for-profit, the area number of short-term general hospitals, area number of hospitals per 100,000 population, area average beds per hospital, the number of area generalist physicians, specialists physicians, and pediatricians per 1,000 population, and the average area 1990 Medicare AAPCC; (3) including squares of urbanization variables; (4) including in the sample hospitals that did not have an active delivery service in 1980; (5) including only hospitals in MSAs and measuring HMO market share at the MSA level; and (6) including only hospitals in MSAs and measuring HMO market share with Interstudy's 1996 MSA-level estimate of market share.
} 
do not suggest that pooling the two groups biased the results.

\section{Unobserved heterogeneity}

A potential difficulty with these results is bias from unobserved heterogeneity. Hospitals in some areas may be less prone to adopt new technologies and services than hospitals in other areas. If these differences are not accounted for by the included covariates, estimates of the effects of HMO market share may be biased. We investigate the possibility of bias from unobserved heterogeneity two ways. First, unobserved heterogeneity can be modeled as an additional source of error in the adoption equations. If unobserved heterogeneity is assumed to take a multiplicative form, the hazard becomes:

$$
\lambda_{i}(t)=\theta_{i} \lambda_{0}(t) \exp \left(x_{i}{ }^{\prime} \beta\right)
$$

where $\theta_{i}$ is a random variable that is assumed to be independent of $x_{i}$. One approach to estimating (4) is to assume a distribution for $\theta$ and jointly estimate the parameters of the heterogeneity distribution and the hazard model. A common choice is the gamma distribution. ${ }^{11}$ Column 5 of Table 3 presents results from this approach. The estimated variance of the gamma distribution is different from zero, suggesting some heterogeneity, but the market share coefficients are similar to those estimated without incorporating heterogeneity.

Because this method requires the assumption that $\theta_{i}$ is independent of $x_{i}$, which may not be satisfied, these results are not conclusive proof that there is no heterogeneity bias. Nonetheless, they do suggest that heterogeneity of the form assumed is not a source of bias, and thus lend support to

${ }^{11}$ Assuming a gamma distribution is fundamentally ad hoc, so we also experimented with estimating the distribution of $\theta$ nonparametrically (Heckman and Singer, 1984; Meyer, 1990). In practice, we found it difficult to obtain stable estimates with this model, but in the cases where we did, the results tended to suggest little heterogeneity and no changes in the HMO coefficients. 
the view that unobserved heterogeneity does not explain reduced adoption in high HMO areas.

Another approach is to the problem is to control for adoption patterns of technologies that diffused before managed care could have played an important role in adoption decisions. If there is some fixed characteristic of high market share areas that causes them to adopt new technologies more slowly than other markets, this should be reflected in the diffusion of earlier technologies, so controlling for prior technology diffusion should reduce heterogeneity bias. Here, we control for the presence of cardiac intensive care units (CICUs), hospital units specifically designed to care for seriously ill patients with heart attacks and other cardiac conditions. CICUs are similar to NICUs in that they are typically separate units of hospitals designed to treat high-risk patients with a specific set of conditions, set up with specialized equipment and staffed with specialized personnel. The diffusion of CICUs occurred primarily during the 1960s and 1970s, so that they were largely diffused by the early 1980 s when managed care began to play a noticeable role in the U.S. health care system. In 1982, about $28 \%$ of surveyed hospitals reported having CICU beds. About $30 \%$ of hospitals surveyed in 1996 reported having CICU beds. Thus, we suspect the presence of CICUs by the early1980s to reflect any underlying propensity for hospitals to adopt advanced hospital units.

Column 6 of Table 3 present results from a model in which we include controls for the percent of area hospitals that had adopted a CICU by 1982. Column 7 presents results from a model in which we include a variable indicating whether each individual hospital had a CICU by 1982. Hospitals that adopted a CICU by 1982 are more likely to have adopted a NICU, but controlling for CICU adoption does not have a substantial impact on the HMO market share coefficients.

Estimates from models using dummies for areas with market share under and over $15 \%$ are similar, as are results from models where we control for other technologies that diffused in the 1980s and earlier (e.g. CT scanners, diagnostic radiology equipment). We interpret this as evidence that there 
is not some fixed characteristic of areas that leads hospitals in our high market share areas to adopt advanced hospital units technologies more slowly than hospitals in other areas.

\section{Assessing the effects of competition}

The number of competitors that have adopted NICUs may be an important determinant of a hospital's adoption decision. One mechanism by which managed care could influence diffusion patterns is shifting the incentives for hospitals to compete by adopting new technologies. We explore this by augmenting our basic specification to include the availability of NICUs in each hospital's market and an interaction between NICU availability and HMO market share.

Columns 1 and 2 of Table 4 presents results from models in which we include the percent of the other area hospitals that have NICUs and its interaction with HMO market share as time-varying covariates. We restrict the sample to hospitals located in markets with more than 2 or more hospitals, so measures of rival adoption are sensible. The HMO market share coefficients are similar to those reported above. Evaluating the net effect of HMOs at the 1990 mean of the percent of hospitals with a NICU (13.6\%) yields -0.244 and -0.264 in the models without and with state dummies, comparable to the results obtained earlier. The coefficient on the percent of area hospitals with a NICU is negative and significant, suggesting that hospitals are slower to adopt after other hospitals have a NICU. This coefficient fell after 1985, suggesting that as diffusion progressed the impact of another area hospital having a NICU was less and less a deterrent to adoption. The interaction terms are positive, but statistically weak, particularly in the models with state dummies. If anything, these suggest that the presence of HMOs increases the probability that a hospital will respond to rival adoptions by adopting a NICU, inconsistent with the view that HMOs slowed overall adoption by reducing the incentives for a hospital to adopt once a rival hospital had adopted. 
Columns 3 and 4 report results from specifications in which we replace the percent of area hospitals with a NICU with a dummy variable for whether or not another hospital in the market has adopted a NICU to better capture the impact of incentives to be the first adopter. There are no practical differences between these estimates and those in columns 1 and 2.

Separating effects for mid-level and high level units.

A key component of our analysis of the welfare effects of NICU adoption below is the separation of HMO effects on NICUs with varying levels of capabilities. To investigate this, we expand our empirical model to accommodate the adoption of mid-level or high-level units in a competing risks framework. Here, hospitals that did not previously have a NICU may adopt a midlevel NICU $\left(P_{1}\right)$, adopt a high-level NICU $\left(P_{2}\right)$, or continue without adopting either $\left(P_{3}=1-P_{1}\right.$ $\left.P_{2}\right)$. Denoting unit types by $j=1$ for mid level NICUs and $j=2$ for high level NICUs, hospital $i$ 's cumulative probability of adopting a unit of type $j$ by time $t$ as $F_{i, j}(t)$, and the first year in which hospital $i$ is observed to have a unit or is censored as $t_{i}{ }^{*}$, then the probabilities associated with the three outcomes are: $P_{i, 1}=\operatorname{Prob}[$ adopt mid-level unit $]=\left[F_{i, 1}\left(t_{i}^{*}\right)-F_{i, 1}\left(t_{i}^{*}{ }^{*} 1\right)\right] \times\left[1-F_{i, 2}\left(t_{i}^{*}\right)\right], P_{i, 2}=$ Prob[adopt high-level unit $]=\left[F_{i, 2}\left(t_{i}{ }^{*}\right)-F_{i, 2}\left(t_{i}{ }^{*}-1\right)\right] \times\left[1-F_{i, 1}\left(t_{i}{ }^{*}\right)\right]$, and $P_{i, 3}=\operatorname{Prob}[$ censored $]=[1-$ $\left.F_{i, 1}\left(t_{i}{ }^{*}\right)\right] \times\left[1-F_{i, 2}\left(t_{i}{ }^{*}\right)\right]$. Letting $d_{i, 1}=1$ for hospitals that are observed to adopt a mid-level NICU and $d_{i, 2}=1$ for hospitals that adopt a high-level unit, the likelihood function for the data is given by:

$$
L=\prod_{i=1}^{N} P_{i, 1}^{d_{i, 1}} P_{i, 2}^{d_{i, 2}} P_{i, 3}^{1-d_{i, 1}-d_{i, 2}} .
$$

We maximize the logarithm of this likelihood function using standard techniques, assuming a proportional hazard for adoption of each NICU type.

Results are shown in Table 5. Most of the effect we observe above is attributable to changes 
in the adoption of mid-level units. The post-1985 HMO market share coefficients for mid-level units are large, negative, and statistically significant. The high-level coefficients are much smaller and statistically insignificant. Before 1985, there is little evidence of an effect of HMOs on adoption of either type of unit.

The fact that we observe impacts on mid-level diffusion but not high-level unit diffusion is perhaps not surprising. Much of the high-level diffusion took place during the 1970 s, before managed care played a significant role in the U.S. health care system. Moreover, the adoption of high-level units was concentrated in the most advanced centers that tend to adopt all new advances. The adopters of mid-level units, on the other hand, were typically smaller hospitals for whom the financial and other market incentives associated with acquiring a new technology often play more important roles in decisionmaking.

\section{The Impact of NICU Availability on Health Outcomes}

Setting up new NICUs is typically very costly, so a slowdown in adoption should generate at least temporary savings. A complete analysis of the impact, though, must also include health outcomes. One important and measurable health outcome related to NICU availability is mortality for high risk infants. Mortality is a serious risk for infants with very low birthweights and other health problems, and outcomes for high risk infants are associated with the level of NICU care they receive (Phibbs et al., 1996).

We write the probability of death as a function of the level of care received:

$$
\operatorname{Pr}[\text { Death }]=P_{N} * M R_{N}+P_{M} * M R_{M}+P_{H}^{*} M R_{H}
$$

where $P_{N}, P_{M}$, and $P_{H}$ are the probabilities that the infant is treated in a hospital with no NICU, a mid-level, or high-level NICU, respectively, and $M R$ denotes the mortality rate associated with 
treatment in a hospital with a given level of care. Our results above suggest that the most important effect of HMOs is to slow the diffusion of mid-level units, which could affect overall mortality rates by forcing some infants to be born in hospitals without NICUs and others into high-level centers. These effects could be offsetting. Since we expect $M R_{H}<M R_{M}<M R_{N}$, caring for very high risk newborns in high-level units rather than mid-level units would tend to improve outcomes, but having some ill newborns end up in hospitals without NICUs rather than in hospitals with even a mid-level unit could worsen outcomes.

To examine the overall impact on outcomes, we examine the impact of level of care received on mortality rates and then the effect of NICU availability on level of care received.

\section{$\underline{5.1 \text { Data }}$}

We use California hospital discharge data linked to birth certificate data and mortality records, which provide the clinical detail necessary to analyze mortality rates controlling for important comorbidities and other risk factors (Phibbs et al., 1999). ${ }^{12}$ Our database includes essentially all singleton births that took place in California between 1990 and 1996, and for each newborn identifies a range of clinical characteristics, demographics, mortality, and the hospitals at which they were treated, including transfers and readmissions out to one year after birth. The database altogether contains records for about 4 million births. To focus on high-risk newborns for whom NICU availability is relevant, we selected very low birth weight (VLBW) infants, those with birth weight between 500 and 1500 grams. VLBW is the leading cause of neonatal death in the United States. Despite American Academy of Pediatric guidelines recommending that all VLBW

\section{California.}

${ }^{12} \mathrm{We}$ focus on California since the detailed linked data we require is only available for 
infants be cared for in high level NICUs, only about one third of California VLBW infants are born in hospitals with the highest level units. Nearly $10 \%$ are born in hospitals with no NICU at all.

Some of our analyses use data on the newborn's residence area. We defined areas using the California's Health Facility Planning Areas (HFPAs), 132 areas defined to approximate selfcontained markets for hospital care in California. We excluded the small number of births that occurred in areas with $<100$ births per year total. Our final sample contains 29,359 births.

\subsection{Level of Care Received and Mortality Rates.}

Our outcome measure is 28-day mortality, defined to include all deaths occurring within 28 days of birth as well as any mortality that occurred in the first year of life if the infant remained hospitalized continuously since birth. To examine the impact of NICU care level, we classify newborns into groups born in hospitals with no NICU facilities, a mid-level NICU, or a high-level NICU. ${ }^{13}$ This does not capture post-birth transfers to higher level hospitals. We investigated the effects of including measures of both level of care in birth hospital and levels of care in hospitals reached by transfers and find that including controls for transfers is cumbersome and does not substantially impact the main conclusions, consistent with previous work (Phibbs et al., 1996).

To estimate the impact of level of care on outcomes controlling for case severity, we use logistic regressions of the form:

$$
\operatorname{logit}(28-D a y \text { MORTALITY })=\beta_{0}+\beta_{1} \text { LEVEL }+\beta_{2} X+\epsilon
$$

\footnotetext{
${ }^{13}$ We base our classification on state filings and contact with hospitals. Following California conventions, we divided hospitals into level I (no NICU), II, II+, and III units. We further stratify level II + units into big (mean census $>15$ ) and small (mean census $<15$ ) units. To correspond to the AHA data, we define "mid level" units as level II and small II+ units, and "high level" units as big level II+ and level III units. We use this method rather than the AHA data itself since the California data are probably more accurate, although we find that the correspondence between the AHA and California data is quite good.
} 
where $L E V E L$ is a set of dummy variables for the level of care received, and $X$ is a set of covariates. We include an extensive set of covariates designed to capture variations in mortality risk of the newborns. These include the baby's sex and birthweight interacted as well as detailed controls for comorbidities as used in previous work (see Phibbs et al., 1996). We also control for the mothers race and education, the use of prenatal care, and the insurance status of the baby. Since we pool data from 1990-96, we include year dummies. Finally, some models include dummy variables for the HFPA of residence, in order to capture persistent demographic or other geographic variation.

Main results for the level of care variables are shown in Table 6. Mortality odds are $38-45 \%$ lower for VLBW infants born in hospitals with high-level units relative to hospitals with no NICU. Computing around the sample average mortality rate (19.0\%), this would translate to reductions of about 7 percentage points in the overall mortality rate. Compared to hospitals with mid-level units, high level hospitals have mortality rates about 1 to 1.5 points lower when evaluated at the mean. These are relatively large effects, but if anything they probably understate the impact of care in the highest level centers, which are likely to take care of newborns that are more severely ill in ways that we do not measure.

\section{$\underline{5.3 \text { NICU Availability and Level of Care Received }}$}

Changes in the availability of NICUs could lead to changes in the level of care received by high risk newborns, which could lead to changes in outcomes. To investigate this, we characterized the availability of NICU services in each newborn's residence HFPA and examined the relationship between availability and the level of care received. We characterized availability for each HFPA by computing the number of hospitals with no NICU, mid-level NICUs, and high level NICUs each year for 1990-1996. To capture variations across areas in population and birth rates, we normalized 
these measures by the average annual number of births.

We model the probability that VLBW infants are born in hospitals with no NICU, a midlevel NICU, or a high level NICU as a function of the availability of different units in the HFPA of residence, controlling for the other covariates used in our mortality models. We estimate the probabilities using a multinomial logistic regression:

$$
\operatorname{Pr}\left[L E V E L_{i}=j\right]=\frac{\exp \left(\beta_{j}^{\prime} x_{i}\right)}{1+\sum_{k=1}^{2} \exp \left(\beta_{k}^{\prime} x_{i}\right)}
$$

where $j=1$ indicates hospitals with no NICU, $j=2$ indicates mid-level NICUs, and high-level NICU is the omitted reference group. We characterize the availability of services in each area by entering the number of hospitals with no NICU, mid-level NICUs, and high-level NICUs per 1000 births as main effects, as well as a complete set of interactions between these variables.

For interpretation, we used the results to compute the derivatives of the probability of being born in a hospital with no NICU, a mid-level NICU, or a high-level NICU with respect to the area availability of different level units:

$$
\frac{\partial P_{j}}{\partial A_{m}}=P_{j}\left[\boldsymbol{\delta}_{j, m}-\sum_{k=1}^{2} P_{k} \boldsymbol{\delta}_{k, m}\right]
$$

where $P_{j}$ is the probability of receiving care in a level $j \mathrm{NICU} ; A_{m}$ denotes the area-level availability of units of type $m$; and $\delta_{j, m}$ is the net "coefficient" for the effect of area availability of level $m$ NICUs on use of a level $j$ NICU from the multinomial logit, incorporating all of the interaction terms evaluated at sample means. Derivatives are shown in Table 7, scaled to reflect the adoption 
of one unit of a given type in the average newborn's HFPA. ${ }^{13}$ Increases of one mid-level unit in the average area are associated with 16 point increases in the percent of VLBW newborns born in midlevel hospitals, with corresponding drops of about 14 points for high-level units and 2 points for noNICU hospitals. Increases in the number of high-level units are associated with large shifts away from mid-level to high-level units. ${ }^{14}$

\section{$\underline{5.4 \text { Net Mortality Effects }}$}

Increasing the probability that VLBW infants are born in mid-level hospitals would lead to worse birth outcomes. Combining estimates in Table 7 with estimates of the reduction in mortality associated with being born in mid-level and high-level hospitals from Table 6, a composite estimate of the net impact of adding one mid-level unit to an area is an increase of about $0.11 \%$ in the mortality rate (evaluated at sample mean values).

One can also obtain analogous predicted mortality changes directly, estimating a logistic regression of 28-day mortality on area availability of NICUs. We estimated such a model, using the same specification of area NICU availability described above and including the same covariates. Results were quite similar: evaluated around the sample mean, an increase of one mid-level unit was predicted to increase mortality by 0.12 percentage points. Increases in high-level units were predicted to reduce mortality by 1.5 percentage points.

\section{Conclusions}

${ }^{13}$ The HFPA in which the average birth took place has 11,000 births, so we scale by 0.09 $(1 / 11=0.09)$.

${ }^{14}$ These results are based on models that do not include area dummies. Results from models that do include them are similar. 
Increases in HMO activity slowed the diffusion NICUs during the 1980s and 1990s, primarily by slowing the adoption of mid-level units. We take this as evidence that the changes in incentives that managed care brings about can influence technology diffusion in health care. There are a number of potential mechanisms by which managed care could influence adoption patterns. One possibility is that managed care could influence firms strategic responses to potential or previous adoption by rivals in such a way as to bring about slower adoption overall. Our analysis of competition between firms, however, suggested that this was not likely the case. Rather, we suspect that managed care leads to slower adoption by reducing profitability through reductions in the revenues hospitals receive for NICU services or reductions in demand for NICU care, or both.

Our results most directly show that the time to adoption of a NICU was longer in highmanaged-care relative to lower-managed-care markets. This does not prove that high managed care markets will end up with fewer NICUs in equilibrium, although slower adoption time in high managed care markets is consistent with this. It is, in fact, plausible that there could be changes in equilibrium availability. Particularly if managed care shifts demand or reduces payments in ways that are persistent over time, the profitability of adopting a NICU may not improve substantially as long as managed care remains an important force in markets.

Reductions in the adoption of NICUs can have powerful welfare implications by contributing to savings in the form of foregone adoptions and reduced utilization as well as by influencing health outcomes. Contrary to the conventional wisdom that reductions in technology availability are uniformly bad, we find that reductions in the adoption of mid-level units would tend to improve birth outcomes since more high-risk infants are born in higher-level centers when there are fewer mid-level centers around. These results thus suggest that managed care could improve welfare by reducing costs and improving outcomes in this case. We stress, though, that there are 
other ways in which slower adoption of mid-level NICUs could reduce welfare, perhaps by forcing slightly ill newborns into hospitals with no NICU, bringing about to worse outcomes (though probably not mortality). Slower adoption could also reduce future capabilities that could have developed through learning by doing, slow basic research into new techniques, or have other potentially welfare reducing effects.

Extrapolating these results to other technologies should be done with care. Some technologies are high cost and infrastructure intensive like NICUs, but other technologies may have very different characteristics. For example, new genetic screening procedures have quite different characteristics and may be adopted and used in quite different ways. Our results suggest the power of managed care to influence technology adoption, health outcomes, and spending, but a complete understanding will only be obtained by examining broad patterns in health care delivery. 


\section{References}

Aaron, Henry J., Serious and Unstable Condition: Financing America's Health Care. Washington, D.C.: The Brookings Institution, 1991.

Anderson, Gerard F. and Earl P. Steinberg, "To buy or not to buy: Technology acquisition under prospective payment." New England Journal of Medicine, 311:3 (July 19, 1984) 182-185.

Baker, Laurence C., "HMOs and fee-for-service health care expenditures: Evidence from Medicare." Journal of Health Economics, 16:4 (August, 1997) 453-482.

Baker, Laurence C., "Association of Managed Care Market Share and Health Expenditures for FeeFor-Service Medicare Patients," Journal of the American Medical Association 281:5 (February 3, 1999) 432-437.

Baker, Laurence C., Managed Care and Medical Technology Growth: Evidence from MRI," Stanford University, February 2000.

Baker, Laurence C. and Kenneth S. Corts, "HMO penetration and the cost of health care: market discipline or market segmentation?" American Economic Review, 86:2 (May, 1996) 389394.

Baker, Laurence C. and Joanne Spetz, Managed care and medical technology growth, in Frontiers in Health Policy Research, Alan M. Garber, Editor. 1999, MIT Press: Cambridge, MA.

Baker, Laurence C., Paul Heidenreich, Jeffrey Geppert, and Mark B. McClellan, The effect of area HMO market share and treatments, costs, and outcomes for fee-for-service AMI patients, 2000, Stanford University.

Baker, Stephen R., "The diffusion of high technology medical innovation: The computed tomography scanner example." Social Science and Medicine, 13D (1979) 155-162.

Brook, Robert H., "Practice guidelines and practicing medicine: Are they compatible?" JAMA 262:21 (December 1, 1989) 3027-3030.

Banta, H. David, "The diffusion of the computed technology (CT) scanner in the United States." International Journal of Health Services, 10:2 (1980) 251-269.

Chernew, Michael, "The impact of non-IPA HMOs on the number of hospitals and hospital capacity." Inquiry, 32:2 (Summer, 1995) 143-154.

Chernew, Michael E., Richard A. Hirth, S.S. Sonnad, R. Ermann, and A.M. Fendrick, "Managed care, medical technology, and health care cost growth: a review of the evidence" Medical Care Research and Review, 55:3 (September 1998) 259-288;

CIGNA HealthCare, Corporate cost of poor birth outcomes and infant health in America: everybody's business. Bloomfield (CT); 1992.

Clement, Dolores Gurnick, Phillip M. Gleason, and Randall S. Brown, The Effects of Risk Contract HMO Market Penetration on Medicare Fee-For-Service Costs: Final Report, Mathematica Policy Research: Princeton, NJ, December 18, 1992.

Cutler, David M. and Sheiner, Louise, "Managed care and the growth of medical expenditures" Frontiers of Health Policy Research, volume 1, A.M. Garber, ed., MIT Press 1998.

Cutler, David M., and Mark McClellan, "The Determinants of Technological Change in Heart Attack Treatment” NBER Working Paper \#5751, 1996.

Cutler, David M., Mark McClellan, and Joseph Newhouse, "The Costs and Benefits of Intensive Treatments for Cardiovascular Disease" NBER Working Paper \#W6514, April 1998.

Feldman, Roger and Bryan Dowd, "Is there a competitive market for hospital services?" Journal of Health Economics, 5 (1986) 277-292.

Feldman, Roger, Bryan Dowd, and Gregory Gifford, "The effect of HMOs on premiums in 
employment-based health plans." Health Services Research, 27:6 (February, 1993) 779-811.

Feldman, Roger, Bryan Dowd, Don McCann, and Allan Johnson, "The competitive impact of health maintenance organizations on hospital finances: An exploratory study." Journal of Health Politics, Policy, and Law, 10:4 (Winter, 1986) 675-698.

Fendrick, A. Mark, Jose J. Escarce, Clyde McLane, Judy A. Shea, and J. Sanford Schwartz, "Hospital adoption of laparoscopic cholecystectomy." Medical Care, 32:10 (October, 1994) 1058-1063.

Frank, Richard G. and W. Pete Welch, "The competitive effects of HMOs: A review of the evidence." Inquiry, 22 (Summer, 1985) 148-161.

Fuchs, Victor, "Economics, Values, and Health Care Reform," American Economic Review 86:1 (March 1996) 1-24.

GHAA, National Directory of HMOs. various years, Washington D.C.: The Group Health Association of America.

Globerman, Steven, "The adoption of computer technology in hospitals." Journal of Behavioral Economics, 11:2 (Winter, 1982) 67-95.

Goldberg, Lawrence G. and Warren Greenberg, "The competitive response of blue cross and blue shield to the growth of health maintenance organizations in northern California and Hawaii." Medical Care, 17:10 (October, 1979) 1019-1028.

Hannan, Timothy H. and John M. McDowell, "The determinants of technology adoption: the case of the banking firm." Rand Journal of Economics, 15:3 (Autumn, 1984) 328-335.

Heckman, J., and B. Singer, "A Method for Minimizing the Impact of Distributional Assumptions in Econometric Models for Duration Data,” Econometrica 52:2 (March 1984) 271-320.

Herrchen, Beate, J.B. Gould, and T.S. Nesbitt. "Vital Statistics Linked Birth/Infant Death and hospital Discharge Record Linkage for Epidemiological Studies." Computers and Biomedical Research, Vol. 31, No. 3, September, 1997.

Hillman, Alan L. and J. Sanford Schwartz, "The adoption and diffusion of CT and MRI in the United States." Medical Care, 23:11 (November, 1985) 1283-1294.

Hillman, Bruce J., John D. Winkler, Charles E. Phelps, Jerome Aroesty, and Albert P. Williams, "Adoption and diffusion of a new imaging technology: A magnetic resonance imaging prospective." American Journal of Roentgenology, 143 (October, 1984) 913-917.

Interstudy, Competitive Edge. various years, Excelsior, MN: Interstudy.

Lee, Robert H. and Donald M. Waldman, "The diffusion of innovations in hospitals: Some econometric considerations." Journal of Health Economics, 4 (1985) 373-380.

Levin, Sharon G., Stanford L. Levin, and John B. Meisel, "A dynamic analysis of the adoption of a new technology: the case of optical scanners." The Review of Economics and Statistics, 69:1 (February, 1987) 12-17.

Makuc, DM, B Haglund, DD Ingram, JX Kleinman, and JJ Feldman, Health Care Service Areas for the United States, Vital and Health Statistics, Series 2, no 112, PHS 92-1386, National Center for Health Statistics: Washington DC, November, 1991.

Mansfield, E. Industrial Research and Technological Innovation: An econometric analysis. New York: Norton and Company, 1968.

McLaughlin, Catherine G., "HMO growth and hospital expenses and use: A simultaneous-equation approach." HSR: Health Services Research, 22:2 (June, 1987) 183-205.

McLaughlin, Catherine G., "The effect of HMOs on overall hospital expenses: Is anything left after correcting for simultaneity and selectivity?" HSR: Health Services Research, 23:3 (August, 1988) 421-441.

Meyer, Bruce D., "Unemployment Insurance and Unemployment Spells," Econometrica 58:4 (July 
1990) 757-782.

Miller, Robert H. and Harold S. Luft, "Does managed care lead to better or worse quality of care?" Health Affairs, 16:5 (September/October, 1997) 7-25.

Newhouse, Joseph P., "Medical care costs: How much welfare loss?" Journal of Economic Perspectives, 6:3 (1992) 3-21.

Noether, Monica, "Competition among hospitals." Journal of Health Economics, 7:3 (September, 1988) 259-284.

Phelps, Charles E., "Diffusion of information in medical care." Journal of Economic Perspectives, 6:3 (Summer, 1992) 23-42.

Phibbs Ciaran S., Janet M. Bronstein, Eric Buxton, Roderic H. Phibbs. 1996. The Effects of Patient Volume and Level of Care on Neonatal Mortality. Journal of the American Medical Association, vol 276: 1054-1059.

Phibbs, Ciaran S., Janet M. Bronstein, Eric Buxton, and Roderic H. Phibbs. The Effect of Linking Discharge Data to Birth Certificate Data on Risk-Adjusted Neonatal Mortality. Draft, Palo Alto VA Medical Center, 1999.

Phibbs Ciaran S., D.H. Mark, Harold S. Luft, D.J. Peltzman, D.W. Garnick, E. Lichtenberg, and S.J. McPhee. Choice of Hospital for Delivery: A Comparison of High-Risk and Low-Risk Women. Health Services Research, 1993;28 201-222.

Prentice, Ross, and L. Gloeckler, "Regression Analysis of Grouped Survival Data with Application to Breast Cancer Data" Biometrics 34 (1978) 57-67.

Reinganum, Jennifer F., "The timing of innovation: research, development, and diffusion" in R. Schmalensee and R.D. Willig eds, Handbook of Industrial Organization, volume 1, Amsterdam: North Holland, 1989, p849-908.

Robinson, James C., "HMO market penetration and hospital cost inflation in California." Journal of the American Medical Association, 266:19 (November 20, 1991) 2719-2723.

Robinson, James C., "Decline in hospital utilization and cost inflation under managed care in California." Journal of the American Medical Association, 276:13 (October 2, 1996) 10601064.

Romeo, Anthony A., Judith L. Wagner, and Robert H. Lee, "Prospective reimbursement and the diffusion of new technologies in hospitals." Journal of Health Economics, 3 (1984) 1-24.

Rose, Nancy L., and Paul L. Joskow, "The diffusion of new technologies: evidence from the electric utility industry" Rand Journal of Economics 21:3 (Autumn 1990) 354-373.

Russell, Louise B., "The diffusion of hospital technologies: some econometric evidence." Journal of Human Resources 12:4 (1977) 482-502

Salkever, David S. and Thomas W. Bice, "The impact of certificate-of-need controls on hospital investment." Milbank Memorial Fund Quarterly, 53 (1976) 185-214.

Saloner, Garth and Andrea Shepard, "Adoption of technologies with network effects: an empirical examination of the adoption of automated teller machines." Rand Journal of Economics, 26:3 (Autumn, 1995) 479-501.

Simpson, James B., "Full circle: the return of certificate of need regulation of health facilities to state control," Indiana Law Review 19 (1986) 1025-1127.

Society of Actuaries, Group Medical Insurance, Large claim database report. Schaumberg (IL); 1996.

Vogt, William B., "Detecting Strategic Behavior in Technology Adoption: the example of magnetic resonance imaging." manuscript, Carnegie Mellon University, March 1997.

Weisbrod, Burton, "The health care quadrilemma: An essay on technological change, insurance, quality of care, and cost containment." Journal of Economic Literature, 29 (June, 1991) 523- 
552.

Welch, W. Pete, HMO market share and its effect on local Medicare costs, in HMOs and the Elderly, Harold S. Luft, Editor. 1994, Health Administration Press: Ann Arbor, MI. p. 231249.

Wickizer, Thomas M. and Paul J. Feldstein, "The impact of HMO competition on private health insurance premiums, 1985-1992." Inquiry, 32:3 (Fall, 1995) 241-251.

Williams R.L. and P.M. Chen, "Identifying the sources of the recent decline in perinatal mortality rates in California," New England Journal of Medicine. 306 (1982) 207-214. 
Table 1 : Summary of NICU Adoption Data

\begin{tabular}{|c|c|c|c|c|c|c|c|}
\hline \multirow[b]{2}{*}{$\begin{array}{l}\text { Survey } \\
\text { Year }\end{array}$} & \multirow[b]{2}{*}{$\begin{array}{l}\text { Hospitals } \\
\text { "At Risk" }\end{array}$} & \multicolumn{3}{|c|}{ Adoptions } & \multirow{2}{*}{\multicolumn{2}{|c|}{$\begin{array}{l}\text { Kaplan- } \\
\text { Meier } \\
\text { Survivor } \\
\text { Function } \\
\text { S(t) }\end{array}$}} & \multirow{2}{*}{$\begin{array}{c}\text { Cumulative } \\
\text { Adoption } \\
\text { Probability } \\
1-\mathrm{S}(\mathrm{t}) \\
\end{array}$} \\
\hline & & $\begin{array}{c}\text { Any } \\
\text { NICU }\end{array}$ & $\begin{array}{l}\text { Mid- } \\
\text { Level } \\
\text { NICU }\end{array}$ & $\begin{array}{l}\text { High- } \\
\text { Level } \\
\text { NICU }\end{array}$ & & & \\
\hline 1980 & 4191 & 413 & 189 & 224 & 40 & 0.902 & 0.098 \\
\hline 1982 & 3738 & 97 & 79 & 18 & 17 & 0.878 & 0.122 \\
\hline 1983 & 3624 & 54 & 46 & 8 & 9 & 0.865 & 0.135 \\
\hline 1984 & 3561 & 54 & 46 & 8 & 41 & 0.852 & 0.148 \\
\hline 1985 & 3466 & 40 & 37 & 3 & 30 & 0.842 & 0.158 \\
\hline 1986 & 3396 & 64 & 57 & 7 & 48 & 0.826 & 0.174 \\
\hline 1987 & 3284 & 52 & 48 & 4 & 60 & 0.814 & 0.186 \\
\hline 1988 & 3174 & 64 & 56 & 8 & 45 & 0.797 & 0.203 \\
\hline 1989 & 3064 & 46 & 43 & 3 & 56 & 0.785 & 0.215 \\
\hline 1990 & 2961 & 29 & 25 & 4 & 52 & 0.777 & 0.223 \\
\hline 1991 & 2880 & 39 & 35 & 4 & 50 & 0.767 & 0.233 \\
\hline 1992 & 2791 & 38 & 35 & 3 & 52 & 0.756 & 0.244 \\
\hline 1993 & 2701 & 33 & 31 & 2 & 81 & 0.747 & 0.253 \\
\hline 1994 & 2587 & 93 & 86 & 7 & 93 & 0.720 & 0.280 \\
\hline 1995 & 2401 & 29 & 28 & 1 & 37 & 0.711 & 0.289 \\
\hline 1996 & 2335 & 35 & 34 & 1 & 2300 & 0.701 & 0.299 \\
\hline
\end{tabular}

Note: The baseline sample is 4,191 hospitals in 1980. The number of hospitals at risk is the number that had not previously adopted or been censored. The number of adoptions is the number of hospitals observed to adopt in the interval between the year indicated and the prior year. All adoptions prior to 1980 are reflected in 1980. Censored observations are those not observed to adopt in the indicated year, and not observed in subsequent years. 
Table 2: Descriptive Statistics for Variables in Hospital Adoption Hazard Models

\begin{tabular}{lcc}
\hline & Mean & Standard \\
& $(1)$ & $\begin{array}{c}\text { Deviation } \\
(2)\end{array}$ \\
\hline & & \\
& & \\
HMO Market Share /10 & 1.330 & $(1.153)$ \\
High Market Share $(>15 \%)$ & 0.357 & $(0.479)$ \\
& & \\
\% Pop non-white & 18.167 & $(14.037)$ \\
\% Pop female age $15-44$ & 22.929 & $(1.789)$ \\
\% Pop college graduate & 17.967 & $(6.073)$ \\
\% Pop high school graduate & 73.890 & $(7.571)$ \\
Per capita income /1000 & 22.358 & $(4.977)$ \\
Births per 1000 pop & 14.188 & $(1.419)$ \\
\% births $<2500$ grams & 7.197 & $(2.308)$ \\
\% Population urban & 6.439 & $(21.491)$ \\
Population /100,000 & 11.664 & $(28.245)$ \\
Population per square mile /100 & 6.322 & $(0.401)$ \\
1=medical school affiliated & 0.201 & $(0.243)$ \\
1=council of teaching hospitals member & 0.063 & $(0.097)$ \\
1=childrens hospital & 0.010 & $(178.364)$ \\
Bed size (1980-1996 average) & 183.928 & \\
& & \\
N & 4191 & \\
\hline & & \\
\hline
\end{tabular}

Note: Market share refers to 1990-1996 average market share. 
Table 3: Results from NICU adoption hazard models

\begin{tabular}{|c|c|c|c|c|c|c|c|}
\hline & $(1)$ & $(2)$ & (3) & $(4)$ & $(5)$ & $(6)$ & (7) \\
\hline HMO Mkt Shr $/ 10$, year $\geq 1985$ & $\begin{array}{l}-0.169 \\
(0.059) \\
{[0.845]}\end{array}$ & - & $\begin{array}{l}-0.235 \\
(0.075) \\
{[0.791]}\end{array}$ & - & $\begin{array}{c}-0.203 \\
(0.125) \\
{[0.816]}\end{array}$ & $\begin{array}{c}-0.239 \\
(0.076) \\
{[0.787]}\end{array}$ & $\begin{array}{l}-0.216 \\
(0.075) \\
{[0.806]}\end{array}$ \\
\hline HMO Mkt Shr $/ 10$, year $<1985$ & $\begin{array}{c}0.008 \\
(0.057) \\
{[1.008]}\end{array}$ & - & $\begin{array}{c}0.006 \\
(0.074) \\
{[1.006]}\end{array}$ & - & $\begin{array}{c}0.015 \\
(0.122) \\
{[1.015]}\end{array}$ & $\begin{array}{c}0.001 \\
(0.074) \\
{[1.001]}\end{array}$ & $\begin{array}{c}0.018 \\
(0.074) \\
{[1.018]}\end{array}$ \\
\hline Market Share $>15 \%$, year $\geq 1985$ & - & $\begin{array}{c}-0.524 \\
(0.129) \\
{[0.592]}\end{array}$ & - & $\begin{array}{c}-0.361 \\
(0.154) \\
{[0.697]}\end{array}$ & - & - & - \\
\hline Market Share $>15 \%$, year $<1985$ & - & $\begin{array}{l}-0.122 \\
(0.120) \\
{[0.885]}\end{array}$ & - & $\begin{array}{c}0.133 \\
(0.144) \\
{[1.142]}\end{array}$ & - & - & 一 \\
\hline $\begin{array}{l}\text { \% Area Hosps with CICU } \\
\text { in } 1982, \mathrm{yr} \geq 1985\end{array}$ & - & - & - & - & - & $\begin{array}{c}0.305 \\
(0.335)\end{array}$ & - \\
\hline $\begin{array}{l}\text { \% Area Hosps with CICU } \\
\text { in 1982, yr }<1985\end{array}$ & - & - & - & - & - & $\begin{array}{c}0.569 \\
(0.309)\end{array}$ & - \\
\hline $\begin{array}{l}\text { Individual hosp had CICU } \\
\text { in } 1982, \mathrm{yr} \geq 1985\end{array}$ & - & - & - & - & - & - & $\begin{array}{c}0.344 \\
(0.112)\end{array}$ \\
\hline $\begin{array}{l}\text { Individual hosp had CICU } \\
\text { in } 1982, \mathrm{yr}<1985\end{array}$ & - & - & - & - & - & - & $\begin{array}{c}0.626 \\
(0.116)\end{array}$ \\
\hline $\ln \left(\sigma^{2}\right)$ for gamma distribution & - & - & - & - & $\begin{array}{c}1.148 \\
(0.116)\end{array}$ & - & - \\
\hline State dummies & No & No & Yes & Yes & Yes & Yes & Yes \\
\hline $\begin{array}{l}\mathrm{N} \text { hospitals } \\
\text { Log-Likelihood }\end{array}$ & $\begin{array}{c}4191 \\
-4163.11\end{array}$ & $\begin{array}{c}4191 \\
-4158.05\end{array}$ & $\begin{array}{c}4191 \\
-4064.24\end{array}$ & $\begin{array}{c}4191 \\
-4065.83\end{array}$ & $\begin{array}{c}4191 \\
-3907.66\end{array}$ & $\begin{array}{c}4191 \\
-4062.31\end{array}$ & $\begin{array}{c}4118 \\
-4032.31\end{array}$ \\
\hline
\end{tabular}

Note: Robust standard errors in parentheses. All models also control for area urbanization, population demographics, births, and hospital characteristics. All models include 16 baseline hazard parameters. 
Table 4: Coefficients from hazard models that include measures of area NICU adoption, for hospitals in areas with 2 or more hospitals

(1)

\section{Coefficients for years $\geq 1985$}

HMO market share $/ 10$

-0.339
$(0.086)$

$-0.292$

$(0.103)$

$-0.349$

$(0.145)$

$-0.309$

$(0.163)$

$\%$ area hosps with NICU,

$\begin{array}{ll}-0.012 & -0.010 \\ (0.006) & (0.007)\end{array}$

$\%$ area hosps with NICU

* HMO market share /10

$\begin{array}{cc}0.007 & 0.002 \\ (0.003) & (0.003)\end{array}$

Other area hosp has NICU

-

Other area hosp has NICU

* HMO market share /10

\section{Coefficients for years $<1985$}

HMO market share /10

$$
-0.033
$$

(0.063)

$-0.021$

(0.079)

$-0.021$

$(0.065)$

$-0.021$

$-0.514$

$-0.443$

(0.192)

(0.202)

0.205
$(0.149)$

0.082

(0.163)

$\%$ area hosps with NICU

$\begin{array}{ll}-0.040 & -0.039 \\ (0.017) & (0.016)\end{array}$

$\%$ area hosps with NICU

$\begin{array}{cc}0.013 & 0.009 \\ (0.006) & (0.006)\end{array}$

1=Other hosp has NICU

$-1$

Other area hosp has NICU

* HMO market share /10

State dummies

No
4152
-4118.41

Yes

-0.587
$(0.247)$

$-0.630$

(0.243)

0.126
$(0.093)$

0.115

-

(0.090)

N

Log-Likelihood

$-4118.41$

4152

$-4022.53$

No
4152
-4118.66

Yes

4152

$-4020.38$

Note: Robust standard errors in parentheses. The sample includes all hospitals in areas with at least 2 hospitals. All equations include controls for hospital characteristics, area urbanization, area demographics, and births per 1000 and percent low birth weight. All models include 16 baseline hazard parameters. 
Table 5: Results from Competing Risk Models for Mid-Level and High-Level NICU Adoption

\begin{tabular}{lcccc}
\hline & $\begin{array}{c}\text { Mid-Level } \\
(1)\end{array}$ & $\begin{array}{c}\text { High-Level } \\
(2)\end{array}$ & $\begin{array}{c}\text { Mid-Level } \\
(3)\end{array}$ & $\begin{array}{c}\text { High-Level } \\
(4)\end{array}$ \\
\hline & & & & \\
HMO mkt shr $/ 10$, year $\geq 1985$ & -0.168 & -0.036 & -0.220 & -0.074 \\
& $(0.062)$ & $(0.166)$ & $(0.080)$ & $(0.190)$ \\
& {$[0.845]$} & {$[0.965]$} & {$[0.803]$} & {$[0.929]$} \\
HMO mkt shr $/ 10$, year $<1985$ & -0.019 & 0.024 & -0.048 & -0.027 \\
& $(0.070)$ & $(0.087)$ & $(0.090)$ & $(0.138)$ \\
& {$[0.981]$} & {$[1.024]$} & {$[0.953]$} & {$[0.973]$} \\
State dummies & & & & \\
N & No & No & Yes & Yes \\
& 4191 & 4191 & 4191 & 4191 \\
\hline
\end{tabular}

Note: Robust standard errors in parentheses. Hazard ratios in brackets. All equations include controls for hospital characteristics, area urbanization, area demographics, and births per 1000 and percent low birth weight. All models include 16 baseline hazard parameters per unit type. 
Table 6: Results from Logistic Regressions of Mortality on Level of Care Received

\begin{tabular}{lcc}
\hline & $\begin{array}{c}\text { No Area Dummies } \\
(1)\end{array}$ & $\begin{array}{c}\text { Area Dummies } \\
(2)\end{array}$ \\
\hline Mid-Level NICU & -0.450 & -0.406 \\
& $(0.068)$ & $(0.088)$ \\
& {$[0.638]$} & {$[0.666]$} \\
& & \\
High-Level NICU & -0.609 & -0.508 \\
& $(0.067)$ & $(0.095)$ \\
& {$[0.544]$} & \\
& & \\
& No & \\
HFPA dummies & & $2902]$ \\
& & -9436.18 \\
L & 29359 & \\
Log Likelihood & -9534.99 & -0.055 \\
& & -0.066 \\
Predicted change in mortality & & \\
rate, relative to a hospital with & & \\
no NICU, evaluated at the & & \\
sample mean mortality rate & -0.077 & \\
Mid Level NICU & & \\
\hline
\end{tabular}

Note: Results are from logistic regression. Robust standard errors in parentheses. Odds ratios in brackets. Models also control for sex, birthweight, comorbidities, mothers education, prenatal care use, expected source of payment, and include year dummies. Predicted mortality rate changes are evaluated around the sample mean of $19.033 \%$. 
Table 7: Probability Derivatives Associated with Changes in Area Availability of NICUs

\begin{tabular}{lccc}
\hline & Derivative of the probability of receiving care in: \\
& No NICU & Mid-Level & High-Level \\
& $(1)$ & $(2)$ & NICU \\
Area Availability of... & & & $(3)$ \\
\hline Hospitals with no NICU & 0.039 & -0.003 & -0.036 \\
Mid-level NICU hospitals & -0.022 & 0.163 & -0.141 \\
High-level NICU hospitals & -0.085 & -0.297 & 0.381 \\
\end{tabular}

Note: values are derived from multinomial logistic regressions that control for patient sex, birthweight, comorbidities, mothers education, prenatal care use, expected source of payment, and include year dummies but not HFPA dummies (see Appendix B). Values are scaled by 0.09 to simulate the adoption of one additional unit of the given type in the average area. 
Figure 1: Number of hospitals with NICUs, 1980-1996

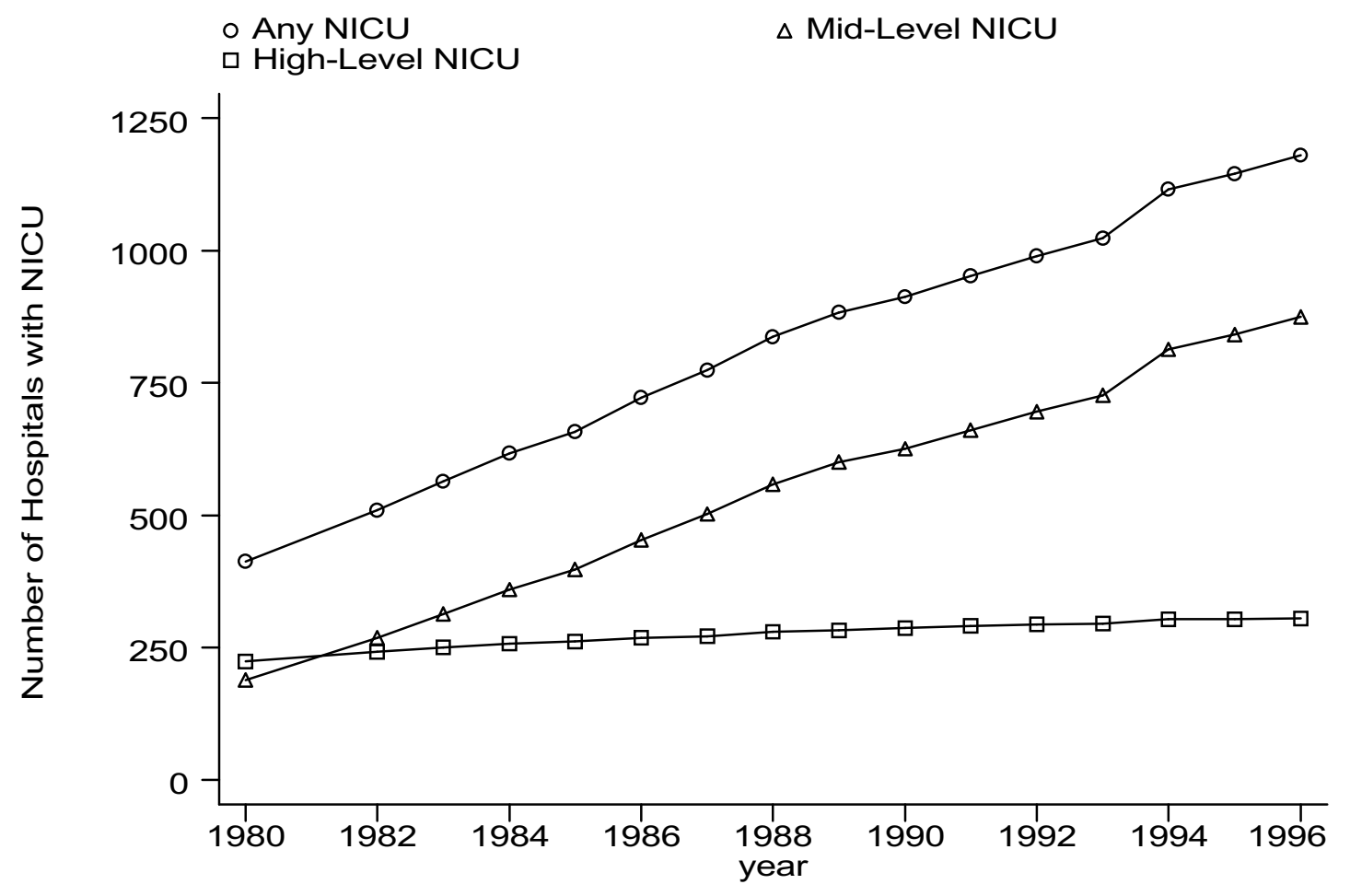

Note: Underlying sample is 4,191 non-federal short-term general or childrens hospitals in non-rural areas actively caring for newborns observed in 1980 . 
Figure 2: Predicted Cumulative Adoption Probabilities for a Hospital with Average Characteristics in a Market with 10\% Market Share and a Market with 30\% Market Share

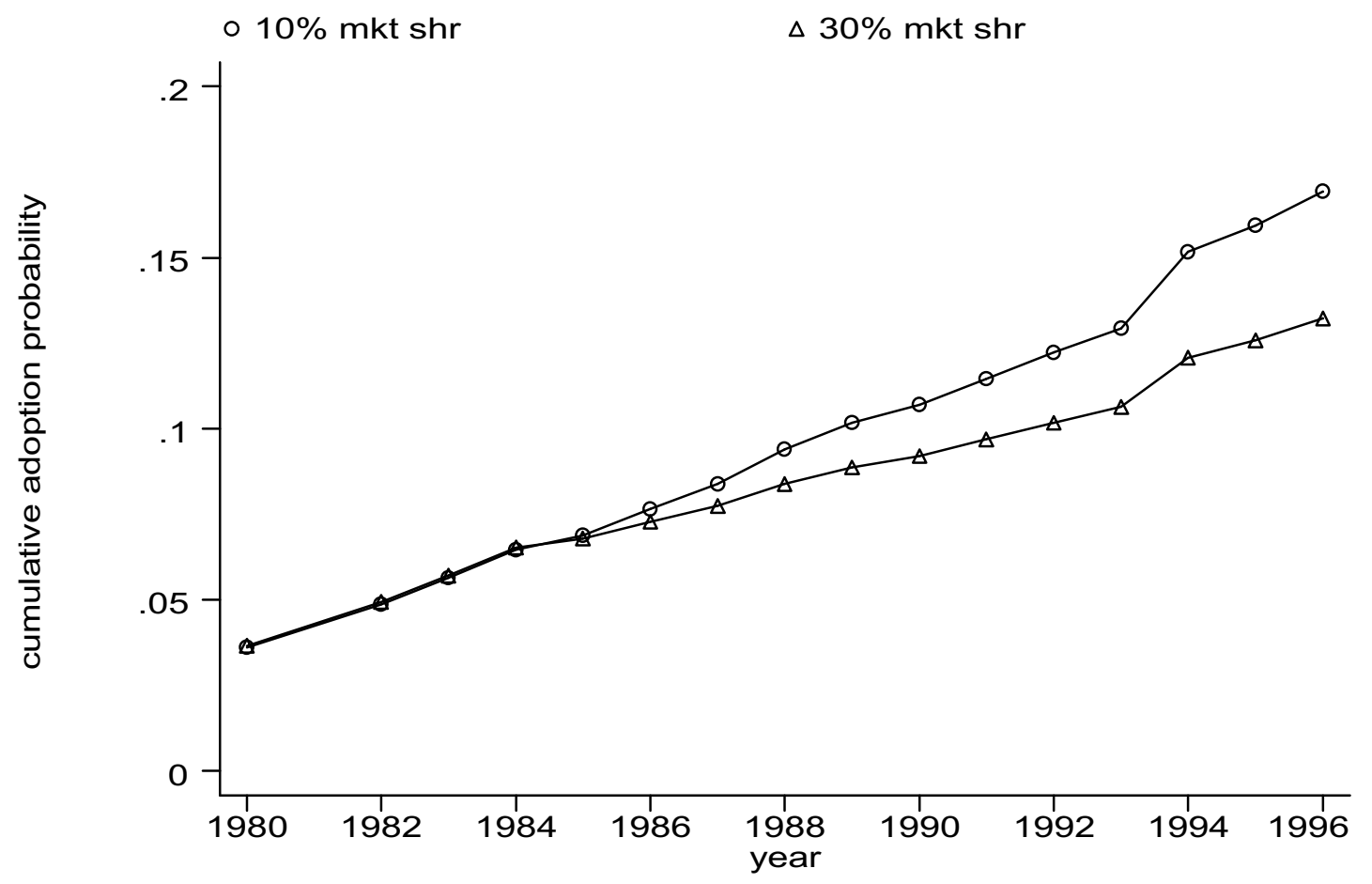

Note: Based on estimates in Table 3, column 3. 